\title{
A EFICIÊNCIA DO SISTEMA MULTIPORTAS DE JUSTIÇA E A APLICAÇÃO NOS CONFLITOS ENVOLVENDO A FAZENDA PÚBLICA
}

\author{
EFFICIENCY OF THE MULTIPORT JUSTICE SYSTEM AND CONFLICT \\ APPLICATION INVOLVING PUBLIC FARM
}

\author{
Bruno Bastos de Oliveira* \\ Maria das Graças Macena Dias de Oliveira** \\ Valter Moura do Carmo***
}

\begin{abstract}
Resumo: O presente artigo propõe-se a analisar o congestionamento dos tribunais, mais especificamente no âmbito da Fazenda Pública. A inquietude da pesquisa pode ser evidenciada em face do seguinte questionamento: Como resolver a morosidade no âmbito fazendário dentro do Poder Judiciário? Assim, intenciona-se analisar como a supremacia e indisponibilidade do interesse público atreladas com a morosidade do Poder Judiciário têm dificultado a entrega da tutela jurisdicional, sendo objetivos específicos a análise da necessidade de meios adequados de resolução de conflitos e como seria a aplicação do sistema multiportas de justiça. Utiliza-se do método de pesquisa bibliográfica, com análise de dados e abordagem qualitativa. Conclui-se pela necessidade de superação de dogmas e a consequente releitura da supremacia e indisponibilidade do interesse público, de forma a inaugurar nova ótica pautada na dignidade da pessoa humana, na qual os interesses públicos e privados deixam de ser contraditórios e se tornam conexos, possibilitando a aplicação do sistema multiportas de justiça nos litígios envolvendo a Fazenda Pública.
\end{abstract}

Palavras-chave: Fazenda Pública; Morosidade; Poder Judiciário; Sistema multiportas; Soluções adequadas.

\begin{abstract}
The present article proposes to analyze the congestion of the courts, more specifically in the scope of the Public Treasury. The unsettling question behind this research can be put as follows: How to solve the slowness in the field of finance within the Judiciary Power? Thus, it intends to analyze how the supremacy and unavailability of the public interest tied to the slowness of the Judiciary Power have made it difficult to deliver the jurisdictional protection, with the specific objectives of the analysis of the necessity

* Advogado e Professor. Consultor Jurídico, especialista na área fiscal. Atualmente faz pós-doutorado em Direito pela UNIMAR - Universidade de Marília - SP, sendo bolsista PNPD. Professor Colaborador do Programa de Pós-Graduação em Direito - Mestrado e Doutorado - da UNIMAR - Universidade de Marília - SP. Doutor em Ciências Jurídicas - Direitos Humanos e Desenvolvimento - pela Universidade Federal da Paraíba. Mestre em Ciências Jurídicas, área de concentração Direito Econômico pela Universidade Federal da Paraíba. Especialista em Direito Tributário pela Universidade do Sul de Santa Catarina. E-mail: bbastos. adv@gmail.com

** Mestranda em Direito, Área de Concentração "Empreendimentos Econômicos, Desenvolvimento e Mudança Social", na Universidade de Marília - UNIMAR. Pós-Graduanda em Direito de Família e Sucessões pela Faculdade de Direito Prof. Damásio de Jesus. E-mail: marianamacenaadv@gmail.com

*** Possui graduação em Direito pela Universidade de Fortaleza - UNIFOR; mestrado em Direito Constitucional pela UNIFOR com período sanduíche na Universidade Federal de Santa Catarina - UFSC e doutorado em Direito pela UFSC, tendo realizado o doutorado sanduíche na Universidade de Zaragoza (Espanha) com bolsa do PDSE da CAPES e período de investigação na Universidade Federal da Paraíba UFPB com bolsa do PROCAD da CAPES. Realizou estágio de Pós-Doutorado na Universidade de Marília - UNIMAR com bolsa do PNPD da CAPES. Professor permanente do Programa de Pós-Graduação em Direito da UNIMAR. Diretor de relações institucionais do CONPEDi. Membro da Comissão de Estudo de Identificação e Descrição da ABNT. Editor da Estudos: Revista de Ciências Humanas e Sociais Aplicadas da UNIMAR e editor-adjunto da Revista do Instituto Brasileiro de Direitos Humanos. E-mail: vmcarmo85@ gmail.com
\end{abstract}


of adequate means of conflict resolution and how the application of the multi-door courthouse system of justice would be. The bibliographical and documentary research method and the qualitative approach are used. It concludes on the necessity of overcoming dogmas and the consequential re-reading of the supremacy and unavailability of the public interest, in order to inaugurate a new perspective based on the dignity of the human person, in which public and private interests cease to be contradictory and become connected, making the application of the multi-door courthouse system of justice possible in disputes involving the Public Treasury.

Keywords: Public Treasury; Slowness; Judiciary Power; Multi-Door System; Appropriate Solutions.

\section{INTRODUÇÃO}

Questão das mais complexas atualmente diz respeito à forma de entrega da tutela jurisdicional no Brasil, especialmente no que tange ao alto índice de congestionamento do Poder Judiciário e a consequente morosidade na solução dos conflitos que são levados a julgamento.

Quando se fala na Fazenda Pública, a situação torna-se ainda mais delicada devido às temáticas abordadas e aos princípios norteadores da personificação do Estado, tais como a supremacia e indisponibilidade do interesse público. Ademais, fato é que o Estado está entre os maiores litigantes, conforme dados fornecidos pelo Conselho Nacional de Justiça.

Ao mesmo tempo em que o Estado precisa buscar meios de se desenvolver, em especial economicamente, depara-se com um cenário completamente desestimulante ao investidor que cogita iniciar uma atividade econômica em âmbito nacional, vez que a atual realidade brasileira impõe exigências típicas de grande burocratização da Administração Pública por meio do complexo sistema tributário, marcado por elevados índices de litigiosidade. Assim, promove-se um ambiente de injustiça fiscal e consequente déficit de cidadania, nocivo ao desenvolvimento, que poderia resultar do incentivo ao investimento privado.

O próprio Conselho Nacional de Justiça $(\mathrm{CNJ})$ vem atuando de modo a incentivar a escolha por mecanismos alternativos para solução de conflitos, "desafogando" o Judiciário. Esses problemas são especialmente identificados nos litígios de natureza fiscal, seja quando o contribuinte reside no polo passivo ou quando o Estado é o demandado, sabendo-se que não há qualquer mecanismo hábil a aliviar a grande litigiosidade fiscal brasileira contemporaneamente.

Sobre a necessidade de se criar mecanismos alternativos para solução de conflitos, em especial os de natureza tributária, cabe lembrar que o Poder Judiciário está prestes a submergir ante o acúmulo de questões a julgar, fato que retarda suas decisões e a efetiva entrega da prestação jurisdicional, ficando o jurisdicionado em situação de delicada insegurança jurídica.

Muitos apontam para o fato de que o sistema tradicional de solução de conflitos está esgotado e precisa urgentemente ser repensado. Exatamente neste ponto vêm à tona discussões sobre a arbitragem e primordialmente sobre a adoção do procedimento arbitral para solução de litígios de natureza tributária, pois tais litígios, tanto na seara administrativa quanto na judicial, se avolumam e chegam ao patamar de completa ineficácia do sistema.

A partir de uma pesquisa bibliográfica, com análise de dados e abordagem qualitativa, serão abordados o conceito e as principais prerrogativas da Fazenda Pública em Juízo, a viabilidade do sistema multiportas de justiça, bem como as novas interpretações dos dogmas e princípios nortea- 
dores do Estado. Por fim, demonstrar-se-á uma possível aplicação do sistema multiportas de justiça no âmbito fazendário e a eficiência que traria a aplicação da justiça aos processos envolvendo a Fazenda Pública.

\section{FAZENDA PÚBLICA EM JUÍZO E SUAS PRERROGATIVAS PROCESSUAIS}

É de extrema importância conceituar a Fazenda Pública em Juízo para que se vislumbre o instituto de uma forma ampla e sirva como base para entender a autocomposição nesta seara.

No dizer de Leonardo Carneiro da Cunha (2017), o termo Fazenda Pública em Juízo representa a personificação do Estado abrangendo as pessoas jurídicas de direito público. Em Direito Processual, quando se alude à mencionada expressão, apresenta-se como sinônimo do Poder Público em Juízo.

Segundo anota Helly Lopes Meirelles (1998, p. 590), “a Administração Pública, quando ingressa em juízo por qualquer das entidades estatais, por suas autarquias, por suas fundações públicas ou por seus órgãos que tenham capacidade processual, recebe a designação tradicional de Fazenda Pública, porque seu erário é que suporta os encargos patrimoniais da demanda".

Cumpre ressaltar que a expressão Fazenda Pública, comumente associada ao termo erário, não se resume a este, tendo em vista, no âmbito judicial, as demandas não versarem exclusivamente sobre a matéria estritamente fiscal ou financeira. Assim, considera-se Fazenda Pública as pessoas jurídicas de direito público no âmbito da fazenda pública em juízo (a União, os Estados, os Municípios, o Distrito Federal e suas respectivas autarquias e as fundações públicas), não estando nesse rol as empresas públicas e as sociedades de economia mista, pois revestem-se da natureza de pessoas jurídicas de direito privado.

Em suma, o termo está consolidado no direito público e privado, e é bom salientar que a Fazenda Pública em Juízo não se resume à matéria tributária, abrange em sua totalidade as matérias que tenham como condão o interesse público e cabendo, portanto, esse interesse ser tutelado pela Administração Pública em Juízo.

Tratando-se da capacidade postulatória da Fazenda Pública em Juízo, sua representação é feita, em regra, por procuradores judiciais, os quais são titulares de cargos públicos privativos de advogados regularmente inscritos na Ordem dos Advogados do Brasil, não sendo necessário haver procuração a representação do vínculo legal mantido com a Administração Pública e o procurador.

A Fazenda pública se faz presente em juízo pela Advocacia Pública, os membros da advocacia pública são advogados a quem se confere a capacidade postulatória, instituição reconhecida nos arts. 131 e 132 da Constituição da República Federativa do Brasil (BRASIL, 1988). Segundo o texto constitucional vigente, o ingresso na advocacia pública dependerá de concurso público e os Procuradores exercerão a representação judicial e consultoria jurídica.

Nessa ordem de ideias, o código de processo civil em seu art. 182 trata também da capacidade postulatória aduzindo que incumbe à Advocacia Pública defender e promover os interesses públicos da União, dos Estados, do Distrito Federal e dos Municípios, por meio de representação judicial, em todos os âmbitos federativos, das pessoas jurídicas de direito público que integram a administração direta e indireta (BRASIL, 2015). 
Isto posto, quando o procurador, o advogado público, atua perante o poder judiciário, é a Fazenda Pública presente em juízo. Incumbe a ele defender os interesses das pessoas jurídicas de direito público no exercício da atividade jurisdicional.

Sob a máxima aristotélica, o princípio da igualdade, positivado na Constituição Federal no art. 5, caput, ensina que a igualdade não consiste em tratar todos de forma igualitária, mas sim, tratar a todos igualmente, na medida das suas igualdades, e todos os desiguais na medida das suas desigualdades.

Tomando como base este ensinamento notório sobre igualdade, cumpre agora a análise das prerrogativas processuais da Fazenda Pública de modo mais justo. Ademais, Mello (2016) afirma que a lei não deve ser fonte de privilégios ou perseguições, mas instrumento regulador da vida social que necessita tratar equitativamente todos os cidadãos.

De tal sorte, o princípio da igualdade no processo civil, como aduz Cunha (2017), está previsto no art. $7^{\circ}$ do Código de Processo Civil e é complementado pelo texto do art. 139 , I, do mesmo código. A igualdade processual assegura a "paridade de armas" e incube-se ao magistrado assegurar a igualdade de tratamento, sendo o princípio do contraditório e ampla defesa intrinsicamente ligado a tal premissa.

Com efeito, as prerrogativas processuais fazendárias têm embasamento constitucional e infraconstitucional e servem para dirimir possíveis desigualdades no procedimento. É possível destacar as seguintes regras especiais conferidas à Fazenda Pública: a remessa necessária (CPC, art.496), prazos diferenciados com intimação pessoal (CPC, art.183), competência territorial (CPC, art. 1.048). A Fazenda Pública em juízo significa a defesa do erário público.

Por tais razões, a fazenda pública faz jus às prerrogativas apresentadas, pois tutela o próprio interesse público em detrimento do particular, ostentando assim condição diferenciada das demais pessoas jurídicas e físicas de direito privado. As prerrogativas processuais não se resumem a simples privilégios, são condições necessárias que viabilizam o exercício do interesse público em juízo, vez que privilégios podem ser, muitas vezes, odiosos, o que não se configura na presente análise.

\section{SISTEMA MULTIPORTAS E A SOLUÇÃO PACÍFICA DOS CONFLITOS: MAIS QUE UMA POSSIBILIDADE, UMA NECESSIDADE}

A fim de alcançar a solução pacífica dos conflitos submetidos ao Judiciário, mais especificamente no âmbito dos processos em que figura como parte a Fazenda Pública, faz-se necessário entender a dogmática do sistema multiportas de justiça. Desde já se afirma que a busca por métodos mais adequados de solução de conflitos se mostra atualmente não como mera possibilidade, mas sim como única alternativa viável de enfrentamento da crise de efetividade que abala a entrega da tutela jurisdicional.

Fato é que o Poder Judiciário não consegue, de forma tranquila, atender aos anseios do jurisdicionado na busca por uma tutela efetiva e em um tempo razoável. Conforme sustentam Bryant Arth e Mauro Cappelletti $(1988$, p. 9) a lógica do ambiente extremamente formal e até certo ponto despótico que é o Judiciário pouco tende a cativar o jurisdicionado. É justamente isso que o sistema multiportas tende a romper. 
O sistema multiportas abre espaço para o avanço das denominadas negociações. Sobre o tema, Bruce Patton, William Ury e Roger Fisher (1922, p. 35) sustentam que a negociação se apresenta como mecanismo comunicativo de ida e volta, com o objetivo de serem encontradas propostas de soluções que atendam os interesses das partes, de maneira complementar e suplementar. Assim, nessa perspectiva, é possível afirmar que o sistema multiportas pressupõe necessariamente o avanço da negociação como parâmetro fundamental.

Conforme aduz Nancy Andrighi e Gláucia Falsarella Foley (2008, p. 1):

Para o sistema operar com eficiência, é preciso que as instâncias judiciárias, em complementaridade à prestação jurisdicional, implementem um sistema de múltiplas portas, apto a oferecer meios de resolução de conflitos voltados à construção do consenso - dentre eles, a mediação.

Diferentemente "dos meios alternativos de resolução de conflitos", o sistema multiportas de justiça não entende que os meios, mediação, conciliação, negociação e arbitragem, não são "alternativos", mas sim "adequados". Ou seja, não se buscaria a melhor alternativa, mas sim o método adequado que possibilitasse a efetiva resolução do conflito. Nessa ordem de ideias, Cunha (2017, p. 639), em sua consagrada doutrina sobre a Fazenda pública em Juízo, aduz que:

Para cada tipo de controvérsia, seria adequada uma forma de solução, de modo que há casos em que a melhor solução há de ser obtida pela mediação, enquanto outros, pela conciliação, outros, pela arbitragem e, os que se resolveriam pela decisão do juiz estatal.

Sobre a eficácia do sistema multiportas, Lília Maia de Morais Sales e Mariana Almeida de Sousa destacam que nele há o reconhecimento do fato de que as partes, bem como determinados conflitos, são melhor assistidos por métodos específicos de resolução de conflitos. No sistema multiportas, o litigante é canalizado para a porta correta à solução do conflito especificamente considerado. Afirmam as autoras que "as multiportas têm o poder de fazer com que todos os serviços de resolução de conflitos estejam disponíveis em um único local, incluindo aí a seleção de entrada, passo inicial" (SALES; SOUSA, 2011, p. 209).

Com efeito, a expressão multiportas decorre de uma metáfora: seria como se houvesse, no átrio do fórum, várias portas; a depender do problema apresentado, as partes seriam encaminhadas para a porta da mediação, ou da conciliação, ou da arbitragem, ou da própria justiça estatal.

No Brasil, a utilização do sistema multiportas de justiça ainda é mínima se comparada com os Estados Unidos, é o que se denomina de sistema multi-door courthouse, o qual tem o objetivo fornecer o melhor método para a resolução de um dado conflito.

Por esse prisma, o cidadão teria à disposição várias alternativas para solucionar um conflito. O objetivo do sistema multiportas é buscar formas de solução de conflitos que substituam o tradicional sistema judicial de solução de litígios ou que essas novas formas possam coexistir com a tutela jurisdicional estatal (BRANDÃO, 2014).

No presente artigo, o sistema multiportas de justiça, idealizado nos Estados Unidos, vislumbra-se como uma solução pacífica dos conflitos necessária para auxiliar a atividade jurisdicional estatal a encontrar o meio mais adequado de solução do litígio. Segundo Eriberto Marin e Nivaldo dos Santos: 


\begin{abstract}
A garantia de acesso ao direito e aos tribunais requer mecanismos de proteção jurídicojudiciária individual ou transindividual por meio de exigência de procedimentos adequados de acesso e realização do direito. Desse modo, o acesso ao direito pode resultar em manifestação simultânea de uma proteção jurídica imediata e efetiva, assegurada pelo exercício de certas prerrogativas, consubstanciadas em garantias processuais e procedimentais por meio de proteção judiciária ou o acesso à via judiciária, erigido em direito fundamental de todo o cidadão (MARIN; SANTOS, 2010, p. 19).
\end{abstract}

O congestionamento no Poder Judiciário não é novidade. Segundo Maus (2000, p. 186): “a sociedade está órfã e o Judiciário é seu superego". Com efeito, esse congestionamento é fruto de diversos problemas como falta de servidores e a litigância excessiva, isso tem gerado uma justiça tardia e ineficaz.

Segundo o Conselho Nacional de Justiça, no projeto "Justiça em Números de 2017”, a taxa de congestionamento mede o percentual de processos que ficaram represados sem solução, comparativamente ao total tramitado no período de um ano. Quanto maior o índice, maior a dificuldade do tribunal em lidar com seu estoque de processos. A taxa de congestionamento líquida, por sua vez, é calculada retirando do acervo os processos suspensos ou sobrestados ou em arquivo provisório (BRASIL, 2017).

O relatório dos “100 Maiores Litigantes”, elaborado pelo Conselho Nacional de Justiça, busca identificar quais são esses principais demandantes e o que pode ser feito para reduzir a litigância excessiva no Brasil (BRASIL, 2011).

Como abordado anteriormente, à Fazenda Pública em juízo correspondem as pessoas jurídicas de direito público a União, os Estados, os Municípios, o Distrito Federal e suas respectivas autarquias e as fundações públicas. Esses entes estão entre os dez maiores litigantes.

Os gráficos elaborados pelo Conselho Nacional de Justiça são cristalinos e demonstram a complicadíssima realidade do Poder Judiciário Brasileiro. São mais de setenta milhões de processos pendentes e mais de vinte milhões de novas demandas. Como demonstrado, a justiça estadual possui setenta e cinco por cento de congestionamento enquanto a justiça federal, setenta e quatro por cento. E a Fazenda pública, no âmbito federal, estadual e municipal, está no topo da tabela dos maiores litigantes.

A despeito disso, após a implantação dos denominados Centros Judiciários de Solução de Conflitos (CEJUSCs) no âmbito dos tribunais estaduais, tem-se vislumbrado um aumento progressivo no número de sentenças homologatórias de acordo, tudo levando a crer que esse é um caminho necessário a ser seguido, conforme figura abaixo: 
Figura 1: Centros Judiciários de Solução de Conflitos na Justiça Estadual, por tribunal

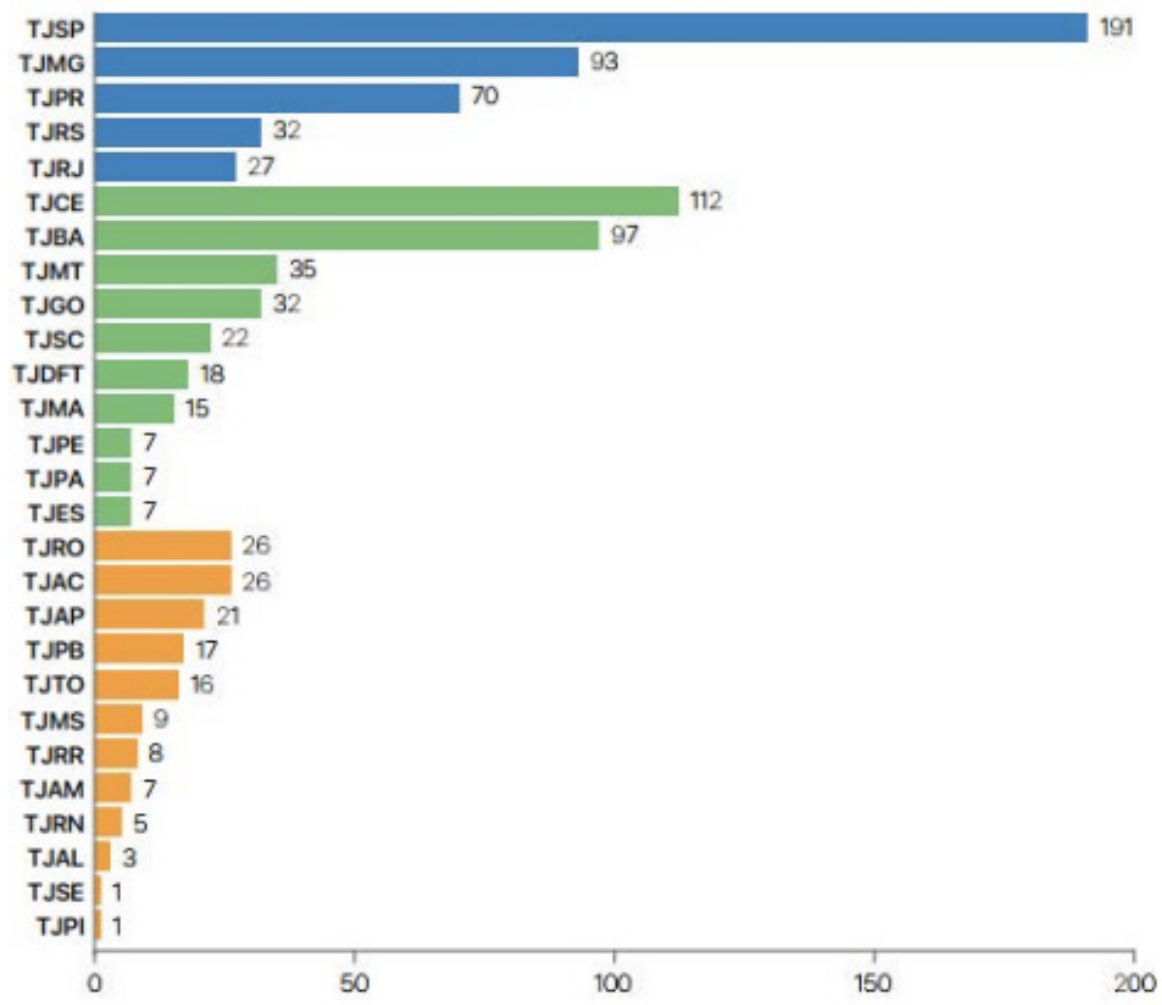

Fonte: Relatório CNJ, Justiça em Números - 2017, p. 125

Acerca da implementação de um sistema multiportas de solução de conflitos, Frank Sander (2000, p. 3) aponta no sentido de existência de quatro eixos centrais, quais sejam: a institucionalização dos meios alternativos; a escolha do método a partir de uma triagem feita por um expert; adequada formação dos profissionais, incluindo advogados e mediadores/conciliadores; (iv) política pública de conscientização, além da adequação da destinação de recursos, apontando-se ainda sobre a certa economia que será gerada ao Poder Judiciário no âmbito desse incentivo. É necessária uma mudança de ponto de vista já que

[...] os recursos não-adversariais, por contemplarem os interesses de todos os envolvidos, por propiciarem que sejam eles os autores das decisões co-construídas e por oferecerem sigilo e celeridade nas negociações, não apenas viabilizam a continuidade de uma relação colaborativa e negocial entre os atores da divergência, como também proporcionam a maior exequibilidade dos acordos prevenindo futuras lides. (MARTINS; CARMO, 2015, p. 33).

Em razão dessa realidade, buscar meios adequados para a resolução dos litígios tem se tornado uma tarefa imprescindível, não apenas para resolver as demandas novas como também as já existentes. No âmbito fazendário, além do volume das demandas, o engessamento dos princípios da Supremacia e Indisponibilidade do interesse público tem tornado essa tarefa ainda mais delicada. 


\section{SUPERANDO OS DOGMAS DA SUPREMACIA E INDISPONIBILIDADE DO INTERESSE PÚBLICO}

Não é uníssono o conceito de interesse público, no entanto é predominantemente utilizado para exprimir o interesse de proveito social ou geral, o interesse da coletividade considerada em seu todo, segundo afirma Mazzilli (2004).

Mello (2016, p. 62), em sua obra Curso de Direito Administrativo, conceitua o interesse público como: "o interesse resultante do conjunto dos interesses que os indivíduos pessoalmente têm quando considerados em sua qualidade de membros da sociedade e pelo simples fato de o serem". Note-se que o interesse público está intrinsecamente atrelado à coletividade que vive em sociedade e busca o bem comum em detrimento do interesse do particular.

Interessante se faz notar que o interesse público consiste na contraposição do interesse do Estado ao interesse do indivíduo, enquanto este consiste na contraposição entre indivíduos em seu inter-relacionamento, no dizer de Mazzilli (2004).

Essas concepções de interesse público são fruto da evolução histórica que, no final do século XIX e começo do século XX, reconfiguraram o que se entendia por interesse público e bem comum, enquadrando-as em uma Espécie de Estado Social de Direito.

Por esse prisma, embora possa haver um interesse público incompatível com um determinado interesse individual, é inconcebível que haja um interesse público discordante dos interesses de cada um dos membros da sociedade. Percebe-se, destarte, uma relação indissociável entre o interesse público e os interesses individuais (MELLO, 2016). Situados entre o interesse público e $\mathrm{o}$ interesse individual encontram-se os interesses transindividuais.

É de clareza ímpar que a noção de interesse público é muito mais abrangente do que, habitualmente, o conflito do particular contra desvios de uma conduta estatal e é muito mais abrangente do que limitar o interesse público ao interesse exclusivamente do Estado. Os interesses públicos correspondem à dimensão pública dos interesses individuais e como uma pessoa jurídica que existe e convive no universo jurídico, possui interesses que lhe são particulares, individuais, os quais não se confundem com interesse público. Mello faz uma fundada observação:

Esta distinção a que se acaba de aludir, entre interesses públicos propriamente ditos isto é, interesses primários do Estado - e interesses secundários, é de trânsito corrente e moente na doutrina italiana, e a um ponto tal que, hoje, poucos doutrinadores daquele país se ocupam em explicá-lo (MELLO, 2016, p. 66).

Em suma, o interesse público abrange os interesses individuais e os transindividuais. A sociedade é norteada pelo interesse público, entretanto esse interesse é formado por uma coletividade de interesses individuais e nem sempre estão em polos contrários. Os interesses individuais no âmbito fazendário, por causa das temáticas abordadas, acabam refletindo os anseios sociais que estão constitucionalmente resguardados pela Constituição.

O Direito deixou de ser apenas o instrumento de garantia dos direitos do indivíduo e passou a ser visto como meio para a consecução da justiça social, do bem comum, do bem-estar coletivo (DI PIETRO, 2008, p. 64). Em verdade, ao se organizar em sociedade, os indivíduos forneceram ao Estado a função basilar de zelar pelo interesse da coletividade. É por meio dessa função que se manifesta a supremacia do interesse público. 
O princípio da Supremacia do interesse público, mesmo não estando previsto expressamente na Constituição de 1988, é princípio geral do Direito inerente a qualquer sociedade, sendo sua a própria condição de existência da mesma. Considerados por muitos doutrinadores, um supraprincípio é o responsável por ponderar as atividades administrativas, sejam em juízo ou não, a fim de preservar a tutela dos interesses públicos. Na visão de Gustavo Barchet:

A própria razão de existir da Administração é a busca dos interesses públicos, e para cumprir a contento sua missão é necessário assegurar que esses interesses, porque pertinentes a toda coletividade, prevaleçam sobre os interesses privados de seus membros (BARCHET, 2011, p. 54).

Não resta dúvida que, por a Administração atuar pelos interesses mais básicos e relevantes do corpo social, deve gozar de superioridade perante os administrados a fim de assegurar a prevalência desses interesses.

É certo que a supremacia do interesse público é basilar para o Estado Democrático de Direito. Ao elevar o interesse público em detrimento do particular, a Constituição da República federativa do Brasil buscou a efetivação da atividade estatal. Por outro prisma, a supremacia do interesse público não pode ser a responsável por impedir a entrega da tutela jurisdicional no âmbito fazendário. Esse princípio deve ser sempre observado, mas não pode ser o empecilho para que se discutam meios adequados de resolução de litígios.

Assim como o princípio da Supremacia do interesse público, o princípio ora abordado não está explícito no art. 37 da Constituição da República Federativa do Brasil, no qual elenca os princípios que regem a administração pública, é, pois, um princípio implícito, mas não menos importante. Como anteriormente afirmado, juntamente com o princípio da Supremacia do interesse público é considerado um supraprincípio do regime jurídico-administrativo.

Decorre do princípio da indisponibilidade do interesse público o poder-dever de agir da administração, enquanto o particular tem a faculdade em seus interesses para que possa escolher o que melhor lhe aprouver, a Administração Pública está em situação diametralmente oposta, pois sempre que a ordem jurídica confere a administração, um poder faz para que determinado interesse público seja satisfeito (BARCHET, 2011).

Isto posto, a administração dos bens e dos interesses públicos não estão entregues à livre disposição da vontade do administrador, o dever de curá-los é nos termos que dispõe a ordem legal, não possuindo, portanto, disponibilidade sobre os interesses públicos. A indisponibilidade do interesse público, embora seja um princípio norteador da administração pública, na visão moderna, não impossibilita que tal princípio seja relativizado.

O Direito está em constante movimento e a crise dos paradigmas do Direito Administrativo não constitui algo novo. As transformações por que passa o Estado agravam o descompasso entre as velhas categorias e as reais necessidades e expectativas das sociedades contemporâneas em relação à Administração Pública. Nesse diapasão, surge a constitucionalização do direito administrativo que pauta a atuação do ente na dignidade da pessoa humana e o situa acima do conceito do interesse público (BINENBOJM, 2005). 
A Carta de outubro trouxe com fundamento do Estado Democrático de Direito a dignidade da pessoa humana. Esse paradigma norteia todo o ordenamento jurídico e Fazenda Pública em Juízo não seria de forma diversa.

As constantes mudanças que enfrenta a sociedade, em especial no âmbito do Poder Judiciário, devem ser observadas para se buscar a efetiva entrega da tutela jurisdicional.

Por esse prisma, ao se desconstruir a indisponibilidade e supremacia do interesse público, reconstruindo sob a ótica constitucional da dignidade da pessoa humana permite-se uma maior abertura para a aplicação de meios adequados a solução dos litígios enfrentados pela Administração Pública em sentido amplo, tal como o sistema multiportas de justiça.

O princípio da supremacia do interesse público sobre o particular como uma sistemática constitucional cidadã, comprometida com a proteção e promoção dos direitos individuais de maneira ponderada e compatível com a realização das necessidades e aspirações da coletividade como um todo. Devendo, portanto, a Administração Pública, em todas as suas esferas, pautar-se na proporcionalidade (BINENBOJM, 2005).

Vale destacar que a proporcionalidade acima referida não busca excluir a supremacia do interesse público, afinal esse é indispensável ao Estado de Bem-estar Social, contudo, ao se utilizar a proporcionalidade, prestigia-se, dependendo do caso, tanto o interesse público como o interesse particular, pois ambos estão intrinsecamente conectados.

O conteúdo constitucional descrito presta-se também como fundamento a negar a colisão entre interesses públicos e privados. Verifica-se que ambas se encontram enraizadas na Constituição, havendo entre eles uma conexão e não uma contradição.

Isto posto, vislumbra-se uma superação de dogmas a fim de propiciar uma constitucionalização da Administração Pública e a valorização do indivíduo por meio da dignidade da pessoa humana. A utilização da proporcionalidade em detrimento da supremacia acarreta que seja observado qual interesse, no caso concreto, deve ser privilegiado. Assemelha-se a isso a utilização da ponderação, na qual ambos os princípios têm o mesmo peso, devendo-se observar qual melhor se encaixa ao caso concreto. No âmbito fazendário, a partir da superação dos dogmas e da conexão existente entre interesse público e privado, deve-se buscar qual interesse será tutelado e qual o meio mais adequado para solução pacífica do litígio.

\section{SISTEMA MULTIPORTAS E OS LITÍGIOS ENVOLVENDO A FAZENDA PÚBLICA}

A Constituição Federal de $1988 \mathrm{em}$ seu art. 5, XXXV, afirma que a lei não excluirá da apreciação do Poder Judiciário lesão ou ameaça a direito. Entretanto, conforme amplamente demonstrado, o congestionamento judicial tem impossibilitado a entrega da tutela jurisdicional, ou, em outros casos, é feita tardiamente. Importante salientar que em ambos os casos acabasse ocorrendo injustiças. Soma-se a isto a questão de a Fazenda pública estar entre os dez maiores litigantes.

O sistema multiportas de justiça surge como uma alternativa para a resolução, principalmente dos processos pendentes, dos litígios. No âmbito fazendário, para aplicação desse sistema, é imprescindível a visão moderna dos institutos da indisponibilidade e supremacia do interesse público. 
A dependência exclusiva de soluções produzidas pelo Poder Judiciário está provocando um estrangulamento do Fisco, vez que, embora o crédito tributário seja "meio de fornecimento para o Estado de receitas necessárias para cumprimento das necessidades públicas básicas" (MENDONÇA, 2014, p. 37), o percentual de recuperação do passivo mediante o ajuizamento de execuções fiscais é inexpressivo e demanda custos elevadíssimos.

Além disso, no sistema atual, o contribuinte também não recebe uma prestação jurisdicional apta a tutelar, de maneira eficaz, os direitos e garantias individuais - constitucionalizados no intuito de evitar as arbitrariedades decorrentes do poder de tributar -, sobretudo em virtude da lentidão e, não raras vezes, atecnia, que caracterizam o julgamento das demandas. A morosidade no julgamento dos processos viola frontalmente o disposto no inciso LXXVIII, inserido no art. $5^{\circ}$ por força da Emenda Constitucional no 45/04, que tratou sobre a Reforma do Poder Judiciário: "a todos, no âmbito judicial e administrativo, são assegurados a razoável duração do processo e os meios que garantam a celeridade de sua tramitação".

Faz-se necessário destacar que essa ineficiência do Estado, ao atuar como único protagonista na busca por soluções para os conflitos existentes entre o Fisco e o contribuinte, está inserida em um contexto mais amplo que reflete uma crise estrutural do Poder Judiciário em si, assoberbado com um número de ações que cresce em progressão geométrica e despreparado para solucioná-las de maneira célere, adequada e eficiente.

Há que concentrar-se no fato de que um dos principais obstáculos atuais "é o próprio processo, a estrutura do sistema processual encontrado em cada ordenamento em seus pontos de incompatibilidade com a efetivação dos novos direitos" (LUCHIARI, 2012, p. 58) e a eficiência prognosticada na solução dos conflitos.

O panorama acerca dos processos judiciais que se referem às controvérsias tributárias confirma o quadro de ineficiência das soluções alcançadas por intermédio do Poder Judiciário. Consoante informações extraídas do Relatório PGFN em Números (Dados de 2017 - Edição 2018), o estoque total da Dívida Ativa da União corresponde ao exorbitante valor de R 2 trilhões de reais (BRASIL, 2018, p. 15).

Contudo, no ano de 2017, apenas 1,08\% desse valor foi recuperado, o que equivale a R\$26,1 bilhões de reais (BRASIL, 2018, p. 10), percentual que, mesmo sendo inexpressivo, representa um pequeno aumento em relação ao ano de 2016, no qual foram recuperados $\mathrm{R} \$ 14,54$ bilhões em débitos da Dívida Ativa da União (0,79\% do estoque que correspondia a R\$ 1,84 trilhão (BRASIL, 2017).

Ademais, segundo gráfico elaborado pela PGFN, do valor recuperado total, apenas 20,23\%, isto é, R\$ 5,28 bilhões são recuperados através da execução forçada, um número verdadeiramente desanimador para as estatísticas do Poder Judiciário, que diariamente recebe uma enxurrada de novas ações já provenientes do insucesso das cobranças pela via administrativa.

A constatação é reforçada pelas informações extraídas do Relatório Justiça em Números (CNJ), pois de acordo com os dados estatísticos coletados, a cada 100 novas execuções fiscais ajuizadas, o Poder Judiciário só consegue encerar 9 processos:

A maior parte dos processos de execução é composta pelas execuções fiscais, que representam $75 \%$ do estoque. Esses processos são os principais responsáveis pela 
alta taxa de congestionamento do Poder Judiciário, tendo em vista que representam aproximadamente $38 \%$ do total de casos pendentes, apresentando congestionamento de $91 \%$ em 2016 - a maior taxa entre os tipos de processos constantes desse Relatório (BRASIL, 2017, p. 109).

O alto índice de demandas que envolvem a matéria tributária também é observado no Supremo Tribunal Federal (STF). Consoante dados recentemente publicados pelo próprio órgão no diagnóstico de "Processos Autuados por Ramo do Direito em 2018" (BRASIL, 2018), o Direito Tributário ocupa a terceira posição, com 2.390 novos processos (10,95\%), ficando atrás apenas do Direito Processual Penal, com 2.747 processos (12,59\%) e do Direito Administrativo e outras matérias de direito público, com 7.848 processos $(35,96 \%)$.

Esse contexto desafia a procura por soluções mais globais, resultantes de uma reflexão crítica, cujo intuito seja não somente otimizar a prestação jurisdicional, almejando a superação dos pontos fracos na condução dos processos pelo Estado-Juiz, mas também impulsionar a utilização de outros mecanismos adequados para resolver esse tipo de controvérsia de maneira efetiva.

Diante desse panorama, percebe-se a dificuldade de realização da Dívida Ativa da União, cujo índice, por ser baixíssimo, implica em um aumento astronômico do estoque fiscal, apesar da quantidade de execuções fiscais diariamente ajuizadas pela Fazenda Pública. A ineficiência na cobrança judicial do crédito tributário é problema recorrente e justamente em razão disso busca-se métodos que possam combater esse aumento do estoque fiscal, gerando assim mis riqueza ao país e proporcionando um ambiente favorável ao novo desenvolvimentismo, como política governamental de desenvolvimento.

Essa realidade fez com que a PGFN (Procuradoria Geral da Fazenda Nacional) adotasse mecanismos alternativos que pudessem surtir algum efeito na cobrança de dívidas ativas, utilizando-se, por exemplo, do protesto extrajudicial das Certidões de Dívida Ativa da União (CDA), matéria discutida nos tribunais e chancelada como constitucional pelo Supremo Tribunal Federal, por ocasião do julgamento da Ação Direta de Inconstitucionalidade n. 5135, em novembro de 2016.

Conforme consta em Estudo Técnico da Consultoria Legislativa da Câmara dos Deputados, elaborado por Jules Michelet Pereira Queiroz e Silva (2016), há o fato de que 75\% do estoque da Dívida Ativa da União estão concentrados nos denominados "grandes devedores" (GDE), cujo débito fiscal ultrapassa R \$ 15 milhões. Em contrapartida, esse grupo representa apenas 0,93\% do número de devedores. Conclui-se daí que grande quantidade de devedores sequer estão com débitos inscritos em dívida ativa, o que representa efetivamente um baixíssimo índice de recuperação de estoque fiscal. Percebe-se que, mesmo diante dessa realidade, as políticas governamentais têm sido encaminhadas no sentido de simples aumento da carga tributária, refletindo decisivamente no setor privado e sendo assim entrave ao desenvolvimento econômico do país.

Logo, a intenção é afastar-se da noção segundo a qual "a preeminência do sistema judicial é tal que outras formas de resolução de disputas são comumente denominadas 'alternativas', o que implica dizer que o litígio é a primeira escolha normal "', haja vista que propõe-se uma convivência harmoniosa entre esses vários mecanismos no ordenamento jurídico brasileiro, sem estabelecer qualquer tipo de hierarquia entre eles. 
A aplicação do sistema multiportas de justiça na Fazenda pública pode ser feita de duas formas: por meios dos advogados e procuradores ou com a implementação de uma junta especializada na análise de qual porta deve ser aberta.

No primeiro caso, os advogados públicos, pois está em análise a Fazenda Pública, podem buscar e propor o meio adequado de solução do conflito, seja de forma preventiva ou já no curso do processo. Ao possuir a capacidade postulatória fazendária, os procuradores possuem as mesmas prerrogativas dos advogados privados, podendo se utilizar da advocacia negocial, mediação, conciliação, arbitragem e da tutela estatal. Sempre levando em consideração quais desses meios será mais efetivo para resolver de maneira célere e pacífica o conflito em tela.

Por sua vez, a implementação da junta especializada serviria como uma análise prévia dos fatos, tal como a utilizada na Corte Superior do Distrito de Columbia, Estados Unidos. Buscandose um diagnóstico do litígio e ofereceriam o meio mais adequado para solucionar o conflito. Essa junta especializada, dentro do próprio Poder Judiciário, não seria responsável por dizer o Direito, mas, sim, faria uma análise a partir do que lhes foi apresentado, emitindo parecer sugerindo através do sistema multiportas de justiça qual o caminho mais adequado.

\section{CONSIDERAÇÕES FINAIS}

A cultura excessivamente adversarial e os problemas existentes em um sistema pautado nessa cultura culminaram no congestionamento do Poder Judiciário. Dentre os litígios destacam-se aqueles que possuem a fazenda pública como ré ou autora. Este cenário resultou em um engessamento judicial.

A superação dos dogmas inaugura uma nova ótica pautada na dignidade da pessoa humana, fundamento da República Federativa do Brasil, demonstra uma conexão, e não contradição, entre os interesses públicos e privados. Permitindo assim que conflitos na seara fazendária deixem de ser adversariais e passem a ser mais cooperativos.

Restou assinalado que se deve buscar mecanismos adequados de resolução de conflitos ante a inoperância dos meios tradicionais. Os problemas reais no monopólio do Poder Judiciário exigem dos pesquisadores uma investigação madura para superar o atual estado das coisas, com vistas a propor mudanças que gerem resultados positivos, até porque a incapacidade de o Poder Judiciário se apresentar como instância efetiva de solução de conflitos afeta decisivamente o desenvolvimento econômico e social do país.

É preciso encontrar mecanismos adequados de solução de conflitos, especialmente naqueles em que a Fazenda Pública figura em juízo. Dessa forma, concluímos que a solução reside essencialmente na concepção e implementação de novos mecanismos de realização de justiça, sem que isso signifique anular o significante e constitucional papel do Poder Judiciário.

O princípio constitucional da eficiência na Administração Pública ao mesmo tempo pressupõe a modernização estatal. A regulamentação e efetivação de meios adequados para solução de litígios está ligado à análise de como o Estado vem mudando e como a implementação desses meios vai ao encontro da necessidade de modernização dos instrumentos estatais, em especial dos mecanismos de solução de controvérsias. 
Nesse sentido, corroborado pelo fato de que não há na $\mathrm{CF} / 88$, qualquer indicativo da existência de monopólio da função jurisdicional em favor do Poder Judiciário, negar a possibilidade de utilização de mecanismos que se mostrem mais adequados e eficazes para solução de conflitos envolvendo a Administração Pública seria afrontar a própria essência do que representaria o verdadeiro interesse público.

O Sistema Multiportas de Justiça, através da aplicação dos meios adequados a resolução pacíficas dos litígios, surge como uma saída para congestionamento do Poder Judiciário, em especial aos litígios pendentes. Seria como se houvesse, no átrio do fórum, várias portas e a depender do problema apresentado, as partes seriam encaminhadas para a porta que mais se adequasse e possibilitasse a resolução pacífica.

O contexto do Estado Democrático cooperativo e eficiente pressupõe a adoção de métodos adequados para solução de conflitos de natureza tributária, resultando, assim, na efetivação de um processo de modernização estatal, nos limites da lei e amparadas na ideia de interesse público.

\section{NOTAS}

1 "The pre-eminence of the court system is such that other forms of dispute resolution are commonly called 'alternative' dispute resolution (or ADR), carring the implication that litigation is the normal first choice" (BLAKE; BROWNE; SIME, 2011, p. 04), tradução livre.

\section{REFERÊNCIAS}

ANDRIGHI, Nancy; FOLEY, Gláucia Falsarella. Sistema multiportas: o Judiciário e o Consenso. Folha de São Paulo, São Paulo, jun. 2008. Disponível em: http://www.justica.gov.br/central-de-conteudo/reforma-do-judiciario/artigos/sistema-multiportas.pdf. Acesso em: 31 maio 2019.

BARCHET, Gustavo. Direito Administrativo. 2. ed. Rio de Janeiro: Elsevier, 2011.

BINENBOJM, Gustavo. Da supremacia do interesse público ao dever de proporcionalidade: um novo paradigma para o direito administrativo. Revista de Direito Administrativo, Rio de Janeiro, v. 239, p. 1-32, jan. 2005. Disponível em: http://bibliotecadigital.fgv.br/ojs/index.php/rda/article/view/43855. Acesso em: 21 maio 2019.

BLAKE, Susan; BROWNE, Julie; SIME, Stuart. A practical approach to alternative dispute resolution. Oxford: University Press, 2011.

BRANDÃO, Fernanda Holanda de Vasconcelos. Advocacia negocial: promoção do acesso à justiça pela desjudicialização dos conflitos. João Pessoa: A União, 2014.

BRASIL. Código de Processo Civil, Lei 13.105, de marco de 2015. Disponível em: http://www2.senado. gov.br/bdsf/handle/id/507525. Acesso em: 10 out. 2018.

BRASIL. [Constituição (1988)]. Constituição da República Federativa do Brasil de 1988. Brasília, DF: Presidência da República, 2019. Disponível em: http://www.planalto.gov.br/ccivil 03/Constituicao/ Constituicao.htm. Acesso em: 10 abr. 2019.

BRASIL. Conselho Nacional de Justiça. Justiça em números 2017: ano-base 2016. Brasília: CNJ, 2017, p. 109. Disponível em: http://www.cnj.jus.br/files/conteudo/arquivo/2017/12/b60a659e5d5cb79337945c1dd137496c. pdf. Acesso em: 09 abr. 2019.

BRASIL. Conselho Nacional de Justiça. Os 100 Maiores Litigantes. Brasília, 2011. 
BRASIL. Procuradoria-Geral da Fazenda Nacional. PGFN números: dados de 2016. Brasília: PGFN, 2017. Disponível em: http://www.pgfn.fazenda.gov.br/acesso-a-informacao/institucional/pgfn-em-numeros-2014/ PGFN\%20em\%20Numeros\%202017.pdf. Acesso em: 07 abr. 2019

BRASIL. Procuradoria-Geral da Fazenda Nacional. PGFN números: dados de 2017. Brasília: PGFN, 2018, p. 15. Disponível em: http://www.pgfn.fazenda.gov.br/acesso-a-informacao/institucional/pgfn-em-numeros-2014/pgfn_em_numeros_final_2_web.pdf. Acesso em: 07 abr. 2019.

BRASIL. Supremo Tribunal Federal. Estatísticas do STF. Brasília: STF, 2018. Disponível em: www.stf.jus. br/portal/cms/verTexto.asp?servico=estatistica\&pagina=pesquisaRamoDireito. Acesso em: 30 mar. 2019.

CUNHA, Leonardo Carneiro da. A Fazenda Pública em juízo. 14. ed. Rio de Janeiro: Forense, 2017.

DI PIETRO, Maria Sylvia Zanella. Direito Administrativo. 21. ed. São Paulo: Atlas, 2008.

FISHER, Roger; URY, William; PATTON, Bruce. Getting to Yes: Negotiating Agreement Without Giving In. New York: Penguin Books, 1922.

GARTH, Bryant; CAPPELLETTI, Mauro. Acesso à justiça. Trad. Ellen Gracie Northfleet. Porto Alegre: Fabris Editor, 1988.

LUCHIARI, Valeria Ferioli Lagrasta. Mediação judicial: análise da realidade brasileira - origem e evolução até a Resolução n. 125, do Conselho Nacional de Justiça. Rio de Janeiro: Forense, 2012.

MARIN, Eriberto Francisco Bevilaqua; SANTOS, Nivaldo dos. O acesso ao direito e à justiça. Revista da Faculdade de Direito da UFG, v. 25, n. 1, p. 13-23, 7 out. 2010. Disponível em: https://www.revistas.ufg. br/revfd/article/view/12020/7971. Acesso em: 26 jul. 2019.

MARTINS, Natália Luiza Alves; CARMO, Valter Moura do. Mediação de conflitos socioambientais: uma alternativa à efetivação do direito fundamental ao meio ambiente ecologicamente equilibrado. Revista Catalana de Dret Ambiental, Tarragona, v. 6, n. 2, p. 1-38, jul./dec. 2015. Disponível em: https://revistes. urv.cat/index.php/rcda/article/viewFile/1579/1545. Acesso em: 28 out. 2019.

MAUS, Ingeborg. Judiciário como superego da sociedade: o papel da atividade jurisprudencial na "sociedade órfã". Revista Novos Estudos CEBRAP, São Paulo, n. 58, p. 183-202, nov. 2000.

MAZZILLI, Hugo Nigro. A defesa dos interesses difusos em juízo: meio ambiente, consumidor, patrimônio cultural, patrimônio público e outros interesses. 17. ed. rev., ampl. e atual. São Paulo: Saraiva, 2004.

MENDONÇA, Priscila Faricelli de. Arbitragem e transação tributárias. Brasília: Gazeta Jurídica, 2014.

MEIRELLES, Hely Lopes. Direito Administrativo Brasileiro. 24. ed. São Paulo: Malheiros, 1998.

MELLO, Celso Antônio Bandeira de. Curso de Direito Administrativo. 33. ed. rev. e atual. São Paulo: Malheiros, 2016.

QUEIROZ E SILVA, Jules Michelet Pereira. Execução Fiscal: eficiência e experiência comparada. Estudo Técnico da Consultoria Legislativa da Câmara dos Deputados. Brasília: Câmara dos Deputados, 2016.

SALES, Lília Maia de Morais; SOUSA, Mariana Almeida de. O sistema de múltiplas portas e o Judiciário brasileiro. Revista Direitos Fundamentais e Justiça, v. 5, n. 16, p. 204-220, jul./set. 2011. Disponível em: http://dfj.emnuvens.com.br/dfj/article/view/360/467. Acesso em: 10 fev. 2019

SANDER, Frank. Future of ADR. Journal of Dispute Resolution, Issue 1, Article 5. University of Missouri School of Law Scholarship Repository, 2000. Disponível em: https://scholarship.law.missouri.edu/jdr/ vol2000/iss1/5. Acesso em: 27 out. 2019.

Data de submissão do artigo: Agosto de 2019

Data de aceite do artigo: Novembro de 2019 